\title{
Deep greenhouse gas emission reductions in Europe: Exploring different options
}

\author{
Sebastiaan Deetman ${ }^{\mathrm{a},{ }^{*}}$, Andries F. Hof ${ }^{\mathrm{a}}$, Benjamin Pfluger $^{\mathrm{b}}$, Detlef P. van Vuuren ${ }^{\mathrm{a}, \mathrm{c}}$, \\ Bastien Girod ${ }^{\mathrm{d}}$, Bas J. van Ruijven ${ }^{\mathrm{e}}$ \\ a PBL Netherlands Environmental Assessment Agency, A. van Leeuwenhoeklaan 9, 3721 MA Bilthoven, the Netherlands \\ ${ }^{\mathrm{b}}$ ISI Fraunhofer Institute for Systems and Innovation Research, BreslauerStrasse 48, 76139 Karlsruhe, Germany \\ ${ }^{c}$ Utrecht University, Department of Geosciences, Heidelberglaan 2,3584 CS Utrecht, the Netherlands

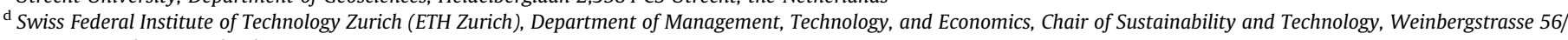 \\ 58, 8032 Zurich, Switzerland \\ e National Center for Atmospheric Research, PO Box 3000, Boulder CO, United States
}

\section{H I G H L I G H T S}

- We model the effects of 15 climate change mitigation measures in Europe.

- We assess the greenhouse gas emission reduction potential in different sectors.

- The measures could reduce greenhouse gas emissions by 60\% below 1990 levels in 2050 .

- The approach allows to explore arguably more relevant climate policy scenarios.

\section{A R T I C L E I N F O}

\section{Article history:}

Received 3 May 2012

Accepted 19 November 2012

Available online 1 January 2013

\section{Keywords:}

Energy modelling

Europe

Climate policy

\begin{abstract}
A B S T R A C T
Most modelling studies that explore emission mitigation scenarios only look into least-cost emission pathways, induced by a carbon tax. This means that European policies targeting specific - sometimes relatively costly - technologies, such as electric cars and advanced insulation measures, are usually not evaluated as part of cost-optimal scenarios. This study explores an emission mitigation scenario for Europe up to 2050, taking as a starting point specific emission reduction options instead of a carbon tax. The purpose is to identify the potential of each of these policies and identify trade-offs between sectoral policies in achieving emission reduction targets. The reduction options evaluated in this paper together lead to a reduction of $65 \%$ of $1990 \mathrm{CO}_{2}$-equivalent emissions by 2050 . More bottom-up modelling exercises, like the one presented here, provide a promising starting point to evaluate policy options that are currently considered by policy makers.
\end{abstract}

(c) 2012 Elsevier Ltd. All rights reserved.

\section{Introduction}

In order to limit global mean temperature increase to less than $2{ }^{\circ} \mathrm{C}$ as mentioned as a goal for international climate policy in both the Copenhagen Accord (UNFCCC, 2009) and the Cancun Decisions (UNFCCC, 2011), stringent emission reductions will be required. For instance, scenarios that limit the increase in radiative forcing to a level of $2.5-3 \mathrm{~W} / \mathrm{m}^{2}$ in 2100 (corresponding to a probability of $50-70 \%$ of staying below $2{ }^{\circ} \mathrm{C}$ ) typically reduce global greenhouse gas (GHG) emissions by $40-80 \%$ by 2050 (Rogelj et al., 2011; van Vuuren and Riahi, 2011; van Vuuren

\footnotetext{
" Corresponding author. Tel.: +3130 2748687; fax: +3130274 4479

E-mail addresses: sebastiaan.deetman@pbl.nl, sebastiaandeetman@hotmail.com (S. Deetman), bgirod@ethz.ch (B. Girod).
}

et al., 2007). Given the rapid emission growth in developing countries, such global emission reductions would require even steeper emission reductions in high-income countries. In fact, the European Union (EU) has indicated that a reduction of European GHG emissions of $80 \%$ to $95 \%$ below 1990 levels would be required by 2050 for a $2{ }^{\circ} \mathrm{C}$ scenario (European Commission, 2011a).

In the last few years, the scientific community has started to explore scenarios that achieve such emission reductions. Examples at the global scale include those by Edenhofer et al. (2010) and van Vuuren et al. (2011). Most studies in this context look at emission reductions in a perfect world in which climate goals are achieved by implementing least-cost emission abatement options, typically, by imposing a global carbon tax or shadow price in model simulations. The focus on cost-optimal scenarios is partly for methodological reasons, but also because modellers 
intend to inform policy-makers about the most cost-effective way to achieve the required emission reductions. Given the focus on this generic price instrument, studies pay little attention to what implementation issues may arise. Clearly, the 'real world' situation is different. Some costly measures are likely to be implemented, while other cost-saving measures are not. For instance, in several European countries expensive PV solar cells are already being deployed, whereas much cheaper or cost-saving measures like building insulation are not always deployed (Boermans and Petersdorff, 2007). In that light, it is useful to also focus on more realistic mitigation pathways. Several scenario studies have taken on this challenge by looking into the impacts of limited participation of countries in climate policy or limited technology availability (Clarke et al., 2009; Lüken et al., 2011). The study presented here takes yet another approach. Instead of implementing a global carbon tax to induce mitigation measures, it starts from specific emission reduction options. We quantify GHG emission reductions resulting from 15 climate change mitigation options in Europe. This scenario study should be seen as explorative and is intended to get a better understanding of European mitigation scenarios and the technical reduction potential resulting from specific mitigation options.

The main objective of this study is to (1) gain more insight into the effectiveness of different specific climate policy measures, and (2) identify trade-offs between sectoral policies in achieving ambitious climate goals. The set of measures is not meant to be exhaustive (see Section 2.3). The aim is not to answer the question whether a European reduction target of $80 \%$ to $95 \%$ is feasible, but instead to provide insight into the effectiveness of some typical measures discussed in the context of fragmented climate policy - and so get a more concrete feeling of the level of effort involved in deep emission reductions.

Section 2 describes the methodology, including the baseline, the models used for this study, and the policy measures that are assessed. The results are discussed in Section 3. Conclusions and a discussion are provided in Section 4.

\section{Methodology}

\subsection{Models used}

To project the emission reductions from the measures, we used the TIMER energy model of the IMAGE Integrated Assessment modelling framework, as described by van Vuuren et al. (2006) and the detailed European power model Power ACE.

TIMER is used to analyse specific mitigation options in industry, transport and the residential sector. It is an energy-system simulation model, describing the demand and supply of 12 different energy carriers for a set of 26 world regions on a yearly basis throughout the end of the century. European energy use is modelled for two regions, i.e., Western Europe and Central Europe. Together, they include all European Union Member States and Norway, Switzerland, the Former Yugoslav Republic of Macedonia, Croatia, Albania, Bosnia \& Herzegovina and Serbia. The TIMER model focuses on several long-term, dynamic relationships within the energy system, such as inertia, learning-by-doing and resource depletion. Energy carriers can be imported or exported from/to other global regions. Final energy demand (for five sectors and eight energy carriers) is modelled as a function of changes in population, in economic activity and structural changes in the sectors based on autonomous and price-induced change in energy intensity (energy conservation) and price-based fuel substitution. Three explicit energy demand sub-modules are used in this study, being a residential energy use module (Daioglou et al., 2012; van Ruijven et al., 2011), a transport energy use module (Girod et al., 2012) and a heavy industry energy use module (Boskaljon, 2010). The demand for electricity can be fulfilled by fossil-fuel or bioenergy based thermal power, hydropower, nuclear power and solar or wind. The model selects specific technologies based on relative costs using a multinomial $\log$ it allocation. The exploration and exploitation of fossil fuels (either for electricity or direct fuel use) is described in terms of depletion and technological development.

The power generation sector plays a very important role in emission reduction strategies. In order to get a more detailed picture of the possibilities to reduce emissions in this sector, the electricity supply model Power ACE has been used. This model has a much higher temporal and spatial resolution than the TIMER model. Power ACE combines a policy-driven diffusion model with optimization techniques, which leads to different pathways than a pure optimization approach. It takes into account national targets regarding renewable electricity (RE), support policies and preferences for certain technologies. This way, currently not costefficient technologies, like photovoltaics, show more realistic growth rates than in optimization approaches.

The diffusion of technologies is described using the agent-based renewable energy investment model PowerACE-ResInvest (Held, 2011). The model contains detailed techno-economic data on specific investments, learning rates and generation potentials for technologies in Europe. The diffusion process is modelled from the perspective of investor agents, which pursue their rationale by evaluating potential sites and national support schemes. The latter are included for the current support scheme, e.g. as quota, and adjusted by policy agents if national targets are over- or unfulfilled. This information is used in the PowerACE-Europe model, which calculates electricity supply in all European countries at hourly time steps up to 2050, based on work by Sensfuß (2007). The hourly generation profiles for wind and solar power are based on meteorological data from weather measurement stations and satellite data. The technological mix complementing the power generation from $\mathrm{RE}$ is optimized in terms of installed capacities and utilisation of power plants, transmission grids and storage facilities. Overall, the Power ACE model cluster covers $14 \mathrm{RE}$ technologies and a range of conventional and nuclear power plant technologies. The modelling approach is described in more detail in Pfluger and Schleich (2012).

Finally, we look briefly into the emission reduction options outside the energy sector, using earlier published work by the full IMAGE model. IMAGE is an integrated assessment model to study the causes and consequences of global (climate) change up to 2100 (Bouwman et al., 2006).

\subsection{Baseline scenario}

The baseline scenario used throughout this study is described in the OECD (2012) Environmental Outlook. The OECD baseline uses projections for GDP growth rates in line with historic development, leading to an average annual global growth rate of $3.5 \%$ and for Europe of $1.9 \%$ between 2010 and 2050. Population assumptions are based on the United Nations medium projections (UN, 2008), in which the global population reaches 9.2 billion people in 2050, 691 million of which in Europe. In the OECD Environmental Outlook, energy system developments and related emissions are elaborated using both the macro-economic model ENV-LINKAGES and the TIMER model. Here, we use the TIMER elaboration, with a more detailed description of the transport system described by Girod et al. (2012). Increase in energy consumption in the baseline roughly follows the projections of the IEA (2010) World Energy Outlook and relate to historical trends and the range found in literature as reviewed by van Vuuren et al. (2012). In the baseline, we assume that no new climate policies are implemented. 


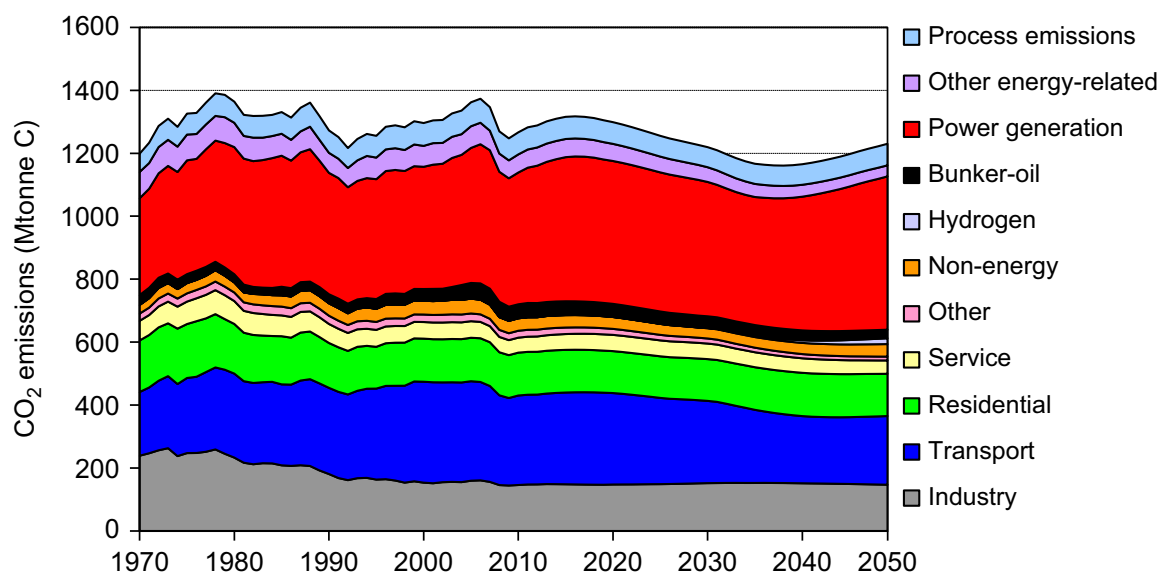

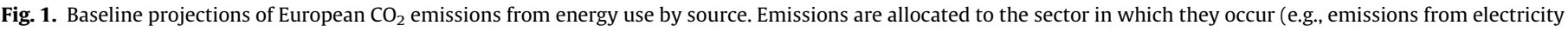
use in the residential sector are allocated to the electricity sector).

Fig. 1 shows the historic and projected baseline $\mathrm{CO}_{2}$ emissions from energy use for the European region. The figure shows that the power generation, industry, transport and residential sectors are the largest direct emitters.

\subsection{Defining mitigation options}

The mitigation options included in this study are described below; for more details, please see Deetman et al. (2011). The measures have been selected based on recent discussions on EU climate policy, and mostly focus on the largest emitting sectors. Where possible we have used measures mentioned in strategic policy documents like the Energy Efficiency Plan and the White Paper on Transport by the European Commission. Some other measures were included based on available literature, as further explained below. While most measures focus on $\mathrm{CO}_{2}$ emissions related to energy use, we have also evaluated the impact of reducing other GHG emissions, such as methane and black carbon, and land-use related $\mathrm{CO}_{2}$ emissions, based on earlier published work using the IMAGE model (PBL, 2010).

Altogether, the measures consist of a wide range of mitigation options, ranging from purely technical measures to policies and lifestyle-related changes. As stated in the Introduction, this study does not attempt to specify an optimal or comprehensive European climate strategy for the $80 \%$ to $95 \%$ reduction target.

\subsubsection{Transport}

Transport currently contributes to about 20\% of European energy-related $\mathrm{CO}_{2}$ emissions. According to model projections, demand for passenger travel will increase by about $40 \%$ and demand for freight transport by about $60 \%$ between 2005 and 2050 (Geurs et al., 2011). Transport-related $\mathrm{CO}_{2}$ emissions, however, are projected to slightly decrease over this period, even without new climate policy, due to on-going energy efficiency improvements and adoption of low-carbon technologies.

The European Commission's roadmap states that a GHG emission reduction of at least $60 \%$ with respect to 1990 is expected from the transport sector by 2050 (European Commission, 2011b). The vision of the EU is to achieve this objective through new vehicle technologies, improved infrastructure and through stimulating new transport patterns.

Scenario studies suggest that there is potential for $\mathrm{CO}_{2}$ emission reduction in the transport sector without limiting the transport volume (Girod et al., 2012). This is important, as the objectives of the European Union are to reduce impacts of transport without curbing or compromising mobility (European Commission, 2011b). This approach is not explicitly aimed at avoiding transport flows, as for example proposed by Dalkmann and Huizenga (2010), thus relies heavily on efficiency improvements, modal shift and alternative vehicles. Even though conventional internal combustion engines (ICEs) have a potential to become more efficient, the most promising developments for reducing climate impacts from passenger cars in the long term are new vehicle propulsion systems. One other approach is to promote high speed trains (HST), a relatively low-carbon intensive form of travel over long distances. In this context, in this study we have focussed on the following measures:

2.3.1.1. A 50\% tax increase on fossil fuel combined with a $35 \%$ subsidy on purchase of electric cars. The current European tax on oil products and natural gas assumed in the model is around 30\% of the fuel price at the filling station. A $50 \%$ increase of the tax gradually implemented between 2015 and 2030 - would roughly represent a cost increase per litre of fuel of about $€ 0.50$ (in 2005 Euros). The subsidy on purchase of electric cars is gradually introduced between 2015 and 2030 as well. Currently, the nonenergy price of battery electric vehicles (BEV) is assumed to be high ( $€ 0.27 / \mathrm{km}$ in 2010 ) in comparison to a typical modern gasoline car ( $€ 0.014 / \mathrm{km}$ ). The non-energy price of the BEV is assumed to decrease to $€ 0.06 / \mathrm{km}$ by 2035 , and the purchase subsidy enhances the competitive position of electric transport further.

2.3.1.2. A 25\% subsidy on capital investments of high speed train transport combined with a departure tax for air travel. Additional to the subsidy on HST, a gradual increase of the average door-todoor speed of high speed rail from 150 in 2005 to almost $175 \mathrm{~km} /$ $\mathrm{h}$ in 2050 is assumed. This compares to no improvement of the speed in the baseline. The departure tax for air travel is gradually implemented and reaches a level that is twice the departure tax implemented, but discontinued, in the Netherlands between 2008 and 2009 (Foster, 2010). The tax amounts to $€ 22$ for continental and $€ 90$ for inter-continental flights, leading to a derived average tax of $€ 0.013 / \mathrm{km}$.

\subsubsection{Residential}

According to the recently published Energy Efficiency Plan 2011 of the European Commission, the greatest energy saving potential lies in buildings (European Commission, 2011a). Buildings are responsible for almost $40 \%$ of final energy consumption, of which about two-thirds is attributable to space heating. 
According to (EU, 2010a) EU Member States shall ensure that by 31 December 2020, all new buildings are nearly zero- energy buildings. We have modelled these ambitions by implementing high insulation standards in newly built buildings. In addition, we included a ban on traditional light bulbs and enforcing efficient appliances as policy options. This results in the following list of measures in the residential sector:

2.3.2.1. Enforcing advanced water heating technologies and high insulation standards in new buildings. Efficiency gains reached by changing from a typical mid-efficiency water heating system to high-efficiency (condensing) boilers generally lead to an improvement in heating efficiency of 10\%-points (DOE, 2011). Additional measures, such as external temperature compensated control and reducing the boiler size, could also lead to significant energy savings (Peeters et al., 2008). In this study a standard is implemented, which leads to a gradual improvement of efficiency in the energy demand for hot water (not used for space heating) of $10 \%$ between 2015 and 2030 . Based on the maximum technical potential for building insulation measures found in Graus et al. (2011), we also include a standard for heating intensities for newly built dwellings of $15 \mathrm{~kJ}$ per square meter of living space per heating degree day (HDD ${ }^{1}$ ), introduced between 2015 and 2030. This reduces the energy demand for both heating and cooling purposes.

2.3.2.2. Banning traditional light bulbs (incandescent lamps). A traditional $60 \mathrm{~W}$ bulb can be replaced by a compact fluorescent lighting (CFL) unit of 11 to $20 \mathrm{~W}$. In this study, we model the effects of a phase-out of incandescent lamps as endorsed by European Union Member States between 2009 and 2012 (EU, 2008), thereby prohibiting the sales after September 2012.

2.3.2.3. Enforcing " $A$ " label appliances. We assume that the average newly purchased appliance (with an average $15 \mathrm{yr}$ lifespan) currently has a " $\mathrm{C}$ " energy label, based on the European energy labelling directive (EU, 2010b). Enforcing sales of " $A$ " label appliances would improve the energy use of dishwashers by $27 \%$, of refrigerators $(\mathrm{A}++)$ by $67 \%$, of tumbler dryers by $48 \%$, of laundry machines by $29 \%$, of televisions by $52 \%$, and of air conditioners by 24\%, all between 2015 and 2030 .

\subsubsection{Industry}

Considerable progress has been made in the energy efficiency of the industry sector in Europe. Still, the sector accounts for about 20\% of the EU's primary energy consumption (European Commission, 2011a). European cement and steel production amounts to almost $30 \%$ of total industrial energy use. Because TIMER has a detailed description of the energy demand of these products, this study specifically focuses on the reduction potential for cement and steel production, by introducing the following industry specific regulations:

2.3.3.1. Enforcing lower clinker ratios and banning standard cement plants in the cement industry. Portland cement, the "ordinary" type of cement, uses high shares of clinker, which is an energyand $\mathrm{CO}_{2}$ intensive intermediate product of cement. Other types of cement could reach comparable material requirements by using less clinker per tonne of cement (Taylor et al., 2006). In this study, a linear decrease of the clinker ratio from 75\% in 2015 to about $65 \%$ by 2030 is enforced. This compares to a ratio of $74 \%$ by 2030 in the baseline. Furthermore, efficient cement production

\footnotetext{
${ }^{1}$ Heating degree days $=\left(18{ }^{\circ} \mathrm{C} \text {-mean outdoor temperature }\right)^{*}$ days; as applied by Isaac and van Vuuren (2009).
}

technologies are enforced by banning newly built standard cement plants from 2015 onwards. The efficient cement production types are about $25 \%$ more efficient than the standard ones.

2.3.3.2. Enforcing use of advanced type steel furnaces. Due to the limited availability of steel scrap, blast furnaces (with or without basic oxygen furnaces) continue to play an important role in the production of steel. Setting efficiency standards for these technologies is a starting point for reducing emissions. In this study, we enforce all newly built steel furnaces to be of the most efficient steel blast furnaces type, with or without carbon capture and sequestration (CCS), from 2015 onwards. These advanced steel furnaces use about half of the energy compared to direct reduction electric arc furnaces, which up to 2050 are the prevailing newly built plants in Europe in the model baseline.

2.3.3.3. Improved energy efficiency through 'good housekeeping'. Energy efficient production can often be achieved through minor process adjustments or optimizations with short payback times, often categorised as 'good housekeeping' measures. Examples are efficient lighting (management), flexibly adjustable motors, optimized compressed air systems (Kaya et al., 2002) and more intensive (preventive) maintenance. In developed countries, housekeeping measures typically enable energy savings in the order of $3.5 \%$ for cement production (Worrell and Galitsky, 2008) and 7.5\% for steel production (Worrell et al., 1999). In this study a gradual implementation of these savings, and a $7.5 \%$ saving on the remaining industries, is introduced between 2015 and 2030.

\subsubsection{Power generation}

Power generation accounts for one-third of European $\mathrm{CO}_{2}$ emissions (UNFCCC, 2012). Because mitigation options analysed in the other sectors affect electricity demand, cleaner power generation is of crucial importance to total European $\mathrm{CO}_{2}$ emission reductions. For the analysis, a different approach than used for the other sectors is taken. As mentioned in Section 2.1, the Power ACE model instead of TIMER is used, because of its higher technological detail. Instead of analysing specific measures, two scenarios are analyzed, using the methodology described in Pfluger and Schleich (2012) and the following assumptions:

2.3.4.1. Implementation of a "decarbonization" policy. This scenario is characterized by a strong willingness to decarbonizes the power sector. As a result, CCS power plants are available and new nuclear power plants can be built in all countries except those that specifically indicated not to use nuclear ${ }^{2}$. Finally, the renewable energy targets for 2020 as described in the National Renewable Energy Action Plans (NREAPs) are implemented (UNFCCC, 2012). Between 2021 and 2050, ambitious national targets for renewable energies are set in the agent-based diffusion model. In many cases, these targets exceed current national longterm targets. The average target of renewable energy is set to $86 \%$ by 2050 , with differences between countries being caused by the available technical potential for RE. The countries apply support schemes such as feed-in tariffs or quota with certificate trading, and adjust their policy if the targets are not met.

We assume that transmission grids between countries and electricity storage facilities are optimized. This optimization procedure seeks a least-cost capacity portfolio and generation

\footnotetext{
${ }^{2}$ In the model, nuclear power plants are not available in the following countries, as they have either a nuclear phase out law in place or have never actively pursued a nuclear energy programme: Austria, Belgium, Cyprus, Denmark, Germany, Greece, Ireland, Italy, Luxembourg, Malta, the Netherlands, Portugal, Sweden, and Switzerland.
} 
mix based on a carbon tax that increases from approximately $€ 20 / \mathrm{tCO}_{2}$ in 2015 to $€ 80 / \mathrm{tCO}_{2}$ in 2050 , which is between the carbon tax levels found in a study by Nordhaus (2010).

2.3.4.2. "Negative emissions". This scenario is identical to the "decarbonization" scenario, except that it additionally assumes $80 \%$ of the biomass power plants to be equipped with CCS (BECCS) after 2021. The BECCS plants' technical parameters are based on the IEA (Korneef et al., 2011).

\subsubsection{Agriculture}

Agricultural $\mathrm{CH}_{4}$ and $\mathrm{N}_{2} \mathrm{O}$ emissions can be reduced by end-ofpipe measures. Furthermore, $\mathrm{CO}_{2}$ can be sequestered by decreasing and reforesting agricultural land or by increasing the carbon content in agricultural soils. One way to reduce the amount of land needed for agriculture is the introduction of dietary changes (Stehfest et al., 2009). A recent study by PBL lists various emission reduction measures in the agricultural sector, aimed at reducing the demand for agricultural land and subsequent regrowth of natural vegetation (PBL, 2011). Here we use the results for the following mitigation options:

2.3.5.1. Crop yield increase. In many countries, especially in Eastern Europe, there is a gap between actual crop yields and potential yields. In the baseline, the annual increase in crop yield levels off from about $1 \%$ currently to less than $0.5 \%$ by 2050 . Based on (PBL, 2011), crop yields increases are accelerated by 50\%, up to a maximum of $1.5 \%$ per year.

2.3.5.2. Supply-chain efficiency. Post-harvest food losses in developed countries are estimated to be between $2 \%$ and $23 \%$ from production to retail and over one-fifth from retail to consumption (Engström and Carlsson-Kanyama, 2004; Lundqvist, 2009). Based on (PBL, 2011), feed conversion efficiencies are increased by $15 \%$ over baseline and agricultural losses are reduced by $7 \%$ of total produce.

2.3.5.3. Healthy diet. According to Willett (2001), a healthy diet consists of an average level of meat consumption of about $10 \mathrm{~g}$ of ruminant meat, $10 \mathrm{~g}$ of pork, $47 \mathrm{~g}$ of poultry/eggs and $24 \mathrm{~g}$ of fish per person per day. Baseline meat consumption in Europe is much higher. In the healthy diet measure, a convergence to a diet with a meat intake that is $50 \%$ above the diet specified by Willet is introduced, which represents a behavioural change towards a lower meat intake.

2.3.5.4. Forest and protected area management. An expansion of protected areas to $20 \%$ of all biome types is assumed, together with increased timber supply from forest plantations (to meet about $50 \%$ of global demand by 2050) and application of Reduced Impact Logging (RIL) techniques for all selective logging.

\subsubsection{Non- $\mathrm{CO}_{2}$ greenhouse gases}

For several non- $\mathrm{CO}_{2} \mathrm{GHGs}$, at least part of the reduction potential can be achieved at relatively low costs (EPA, 2006). At the moment, there is a special interest in reducing emissions of methane, black carbon and ozone precursors based on the assumed co-benefits for health (UNEP and WMO, 2011). In this study, we consider the following set of emission control measures:

2.3.6.1. Methane emission control. For this study no new model runs were performed, but we rely on methane emission reductions resulting from the same carbon tax as used in the power generation sector. The assumptions in IMAGE are based on Lucas et al. (2007), who projects maximum attainable reductions for several emission categories, including coal production, oil and gas production, enteric fermentation (use of different fodder), reducing emissions from landfills and emission control for sewage and wastewater. Maximum emission reduction levels resulting from methane control on these sources lie between 50 and 90\%, which compares to no abatement policy in the baseline.

2.3.6.2. Black carbon emission control. Black carbon (BC) has a high global warming potential (Reddy and Boucher, 2007) and is also a harmful air pollutant (UNEP and WMO, 2011). Typically, more than $90 \%$ of the $\mathrm{BC}$ is found in the fine fraction of particulate matter $\left(\mathrm{PM}_{2.5}\right)$ (Viidanoja et al., 2002). In the baseline, the development of the emission factors for fine particulate matter is derived from the GAINS model (GAINS, 2011) and is used as an indication of the $\mathrm{BC}$ emission factor development, which shows a steep decline in emission intensity between 2015 and 2030. In this study, we apply the lowest regional values of the emission factor found per sector and per fuel to European emissions. This represents the situation in which the most advanced emission reduction technologies found globally are implemented in Europe, but in fact is only a slight improvement compared to baseline development.

\section{Results}

In Sections 3.1 to 3.6, the effects of the measures per sector are described, without taking account of interactions, synergies and trade-offs between sectors. An overview of the combined effect of all measures is given in Section 3.7.

\subsection{Transport sector}

The measures targeted at private transport defined in Section 2.3.1 (fossil fuel tax and subsidy on purchase of electric cars) increase the travel costs of fossil fuelled cars relative to electric cars. Therefore, electric vehicles change from one of the most expensive passenger car options to the cheapest option from 2035 onwards. Fig. 2 shows the projected effect of these relative price changes on the vehicle fleet shares.

Without the policy measures, battery electric vehicles are not projected to enter the market by 2050 . Implementation of the measures is projected to have a large effect on the vehicle fleet: in this case, more than half of the passenger vehicle fleet would consist of battery electric vehicles by 2050 . However, battery electric vehicles largely replace already quite efficient plug in hybrid electric vehicles, and not gasoline vehicles.

As a result of the measures targeted at public transport (a departure tax on air travel and a subsidy on HST), HST would become cheaper than air travel around 2020, whereas it would remain more expensive without these measures. As a result, demand for air travel is partly replaced by travel by HST, without compromising the total demand for long-range passenger transport in Europe (Fig. 3).

Figs. 2 and 3 show that it is possible, at least in our model, to change the structure of the transportation sector to less $\mathrm{CO}_{2}$-intensive forms of transportation, by increasing the share of electric cars and high speed train. The combination of the emission reduction measures for transport lead to a reduction of direct $\mathrm{CO}_{2}$ emissions of $36 \%$ (Fig. 4). However, the measures strongly increase electricity demand, which cause a sharp increase in $\mathrm{CO}_{2}$ emissions from power generation from about 2030 onwards. The total effect on $\mathrm{CO}_{2}$ emissions thus greatly depends on the carbon intensity of the power generation sector. In Fig. 4, it is assumed that the intensity is the same as in the baseline, which would lead to an overall reduction in transport related $\mathrm{CO}_{2}$ emissions of $13 \%$. Lower carbon intensities of power generation would decrease indirect emissions, increasing overall emission reductions from the transport measures. 


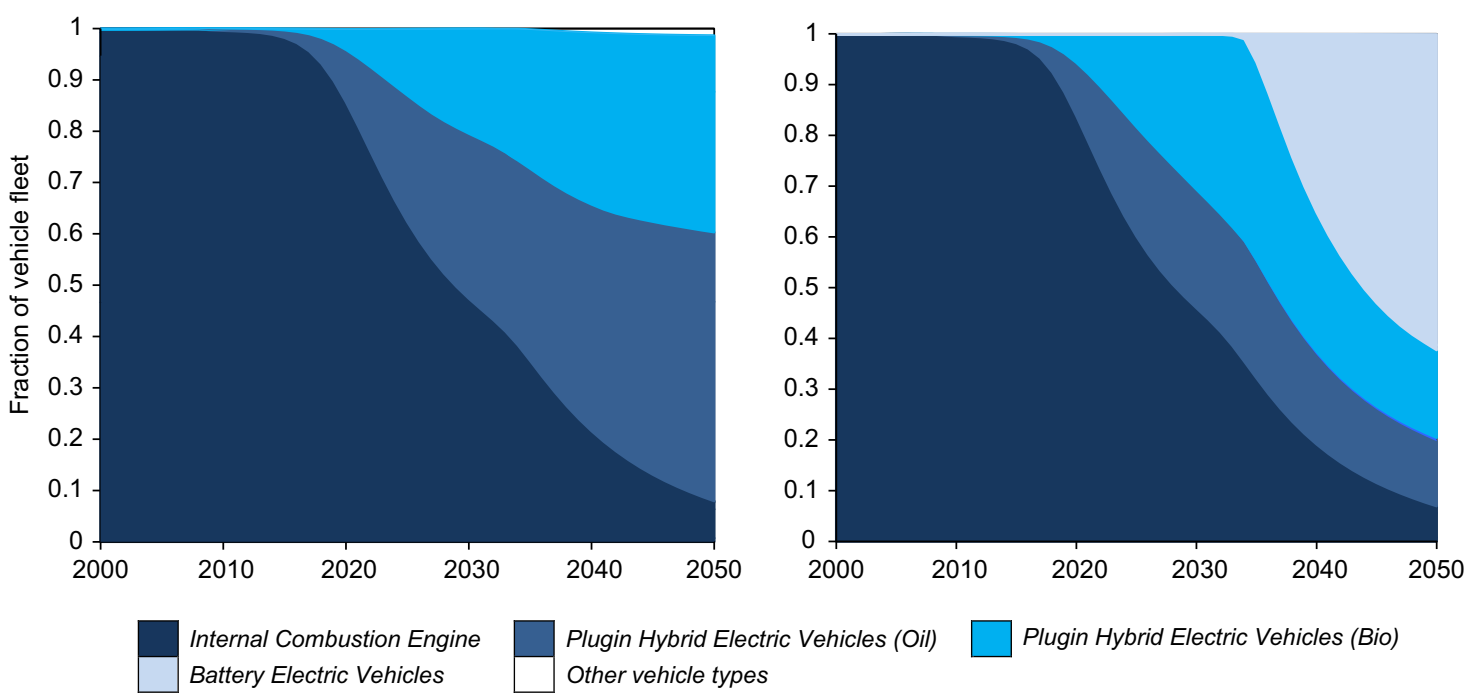

Fig. 2. Shares of passenger car-types in the vehicle fleet, for baseline (left) and implemented measures (right).
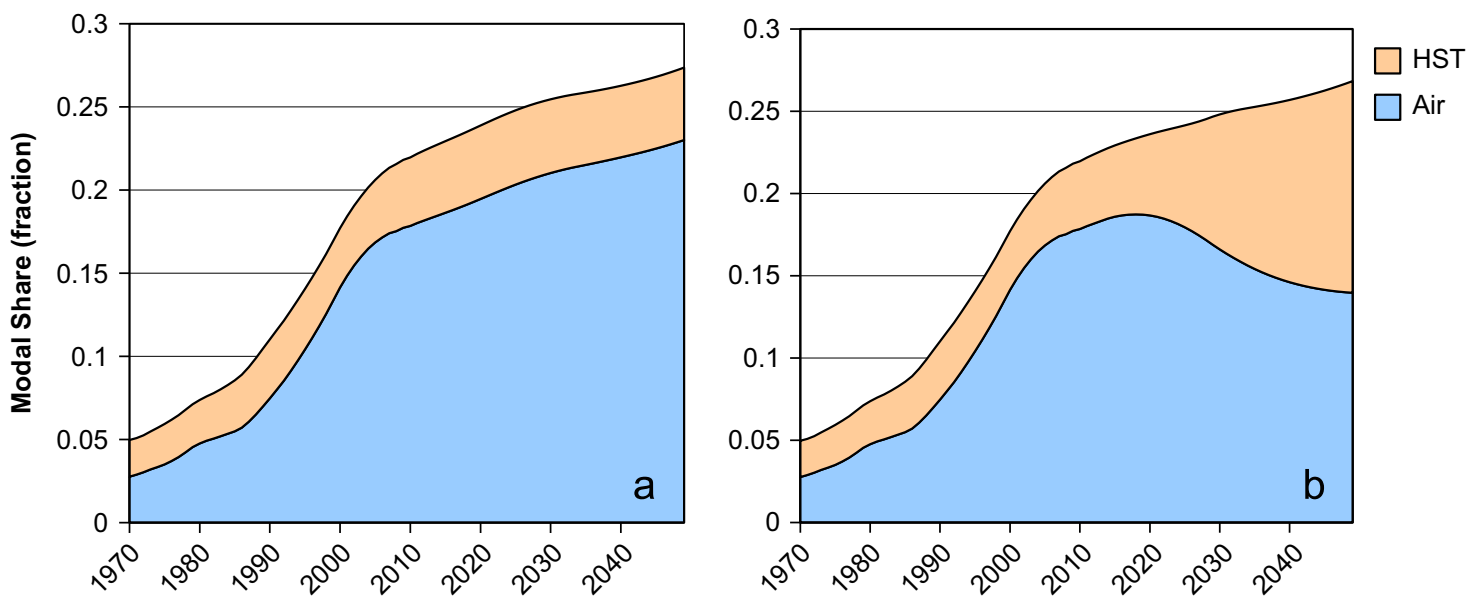

Fig. 3. Modal share for high speed trains (HST) and air travel in Europe (a) in the baseline (b) with a subsidy on HST and a departure tax on air travel.

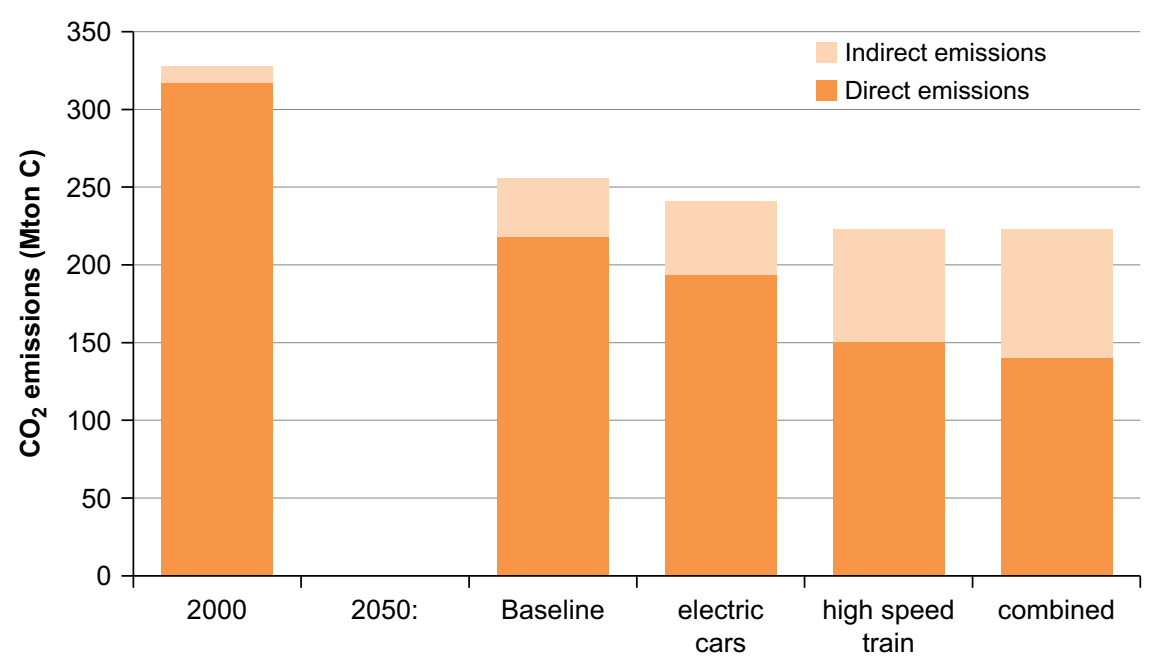

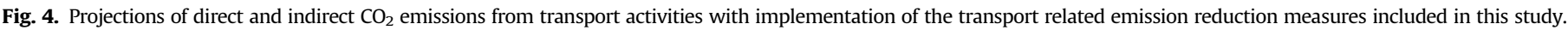

\subsection{Residential sector}

Of the three measures in the residential sector (Section 2.3.2), the enforcement of advanced insulation has the largest effect by far: it could halve energy use for space heating by 2050 compared to baseline. The effects of the measures aimed at improving efficiencies for lighting and appliances is much smaller. This is first of all due to their relatively low energy use: even though 
enforcing " $A$ " label appliances would reduce the electricity use of appliances by $13 \%$ by 2050 , it would only lead to a reduction of $2 \%$ of total residential energy use. Secondly, baseline developments limit the potential reductions for some measures. As CFL units become competitive also without policy measures, the share of advanced lighting increases substantially in the baseline. This means that a ban on traditional light bulbs only speeds up a phase-out, which has anegligible effect on residential energy use.

Combined, the mitigation measures in the residential sector would decrease total direct and indirect residential $\mathrm{CO}_{2}$ emissions by $32 \%$ by 2050 (Fig. 5). A relatively large share of residential $\mathrm{CO}_{2}$ emissions relate to indirect emissions from power generation. Therefore, the total $\mathrm{CO}_{2}$ reductions from the measures strongly depend on the carbon intensity of the power generation sector-which is assumed to be the same as in the baseline here.

\subsection{Industry}

Of the measures in the industry sector, the 'good housekeeping' measures result in the largest reductions (9\%) in final energy consumption compared to baseline. This is because they address energy use in the whole industrial sector, whereas the other measures focus specifically on cement and steel production.

Lowering clinker ratios results in a decrease in demand for clinker of about $12 \%$ compared to baseline by 2050. Banning standard cement plants has a negligible effect, because even without the ban a gradual switch to advanced installations would occur.
Combined, these measures lead to a decrease of only $1 \%$ of industrial final energy use.

Due to the ban on less efficient steel furnaces, all newly built stock consist of advanced coal blast furnaces (Fig. 6). The new stock composition leads to an expected $4 \%$ drop in total industrial final energy use in 2050 compared to baseline.

The combination of all measures in the industry sector would result in a reduction of total industrial $\mathrm{CO}_{2}$ emissions by $15 \%$ (Fig. 7). More than half of the remaining emissions consist of indirect emissions from the power generation sector, again indicating the importance of the carbon intensity of power generation in total $\mathrm{CO}_{2}$ reductions.

\subsection{Power generation sector}

As elaborated in Section 2.3.4, $\mathrm{CO}_{2}$ emission reductions from the power generation sector are modelled using the Power ACE model. Fig. 8 shows the resulting structural composition of the power generation sector.

In the mitigation scenarios, the generation mix in 2050 is radically different than today. Around 2020-2030 gas-fired power plants are in many cases used for base load as a consequence of the $\mathrm{CO}_{2}$ tax. Later in the century, the share of renewable energy, especially wind power, increases sharply. By 2050, wind power accounts for $43 \%$ of total energy supply, while the total share of renewable energy is $83 \%$. Fluctuating sources like wind and photovoltaics make up $68 \%$ of all renewable electricity generation. The high share of RE sources in the power sector lies well

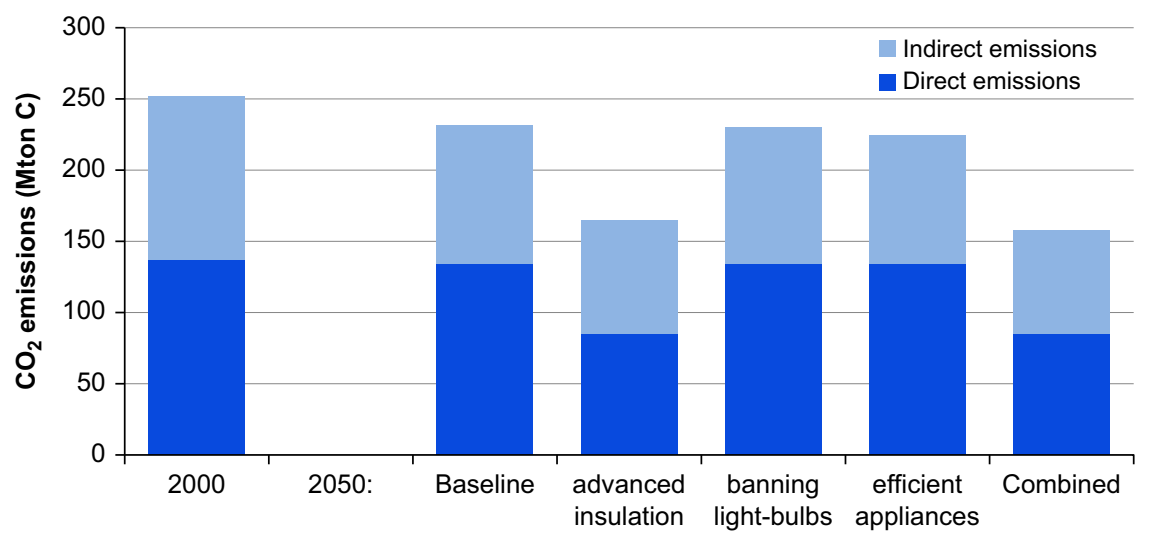

Fig. 5. Total European $\mathrm{CO}_{2}$ emissions from the residential sector with implementation of the three energy saving measures included in this study.
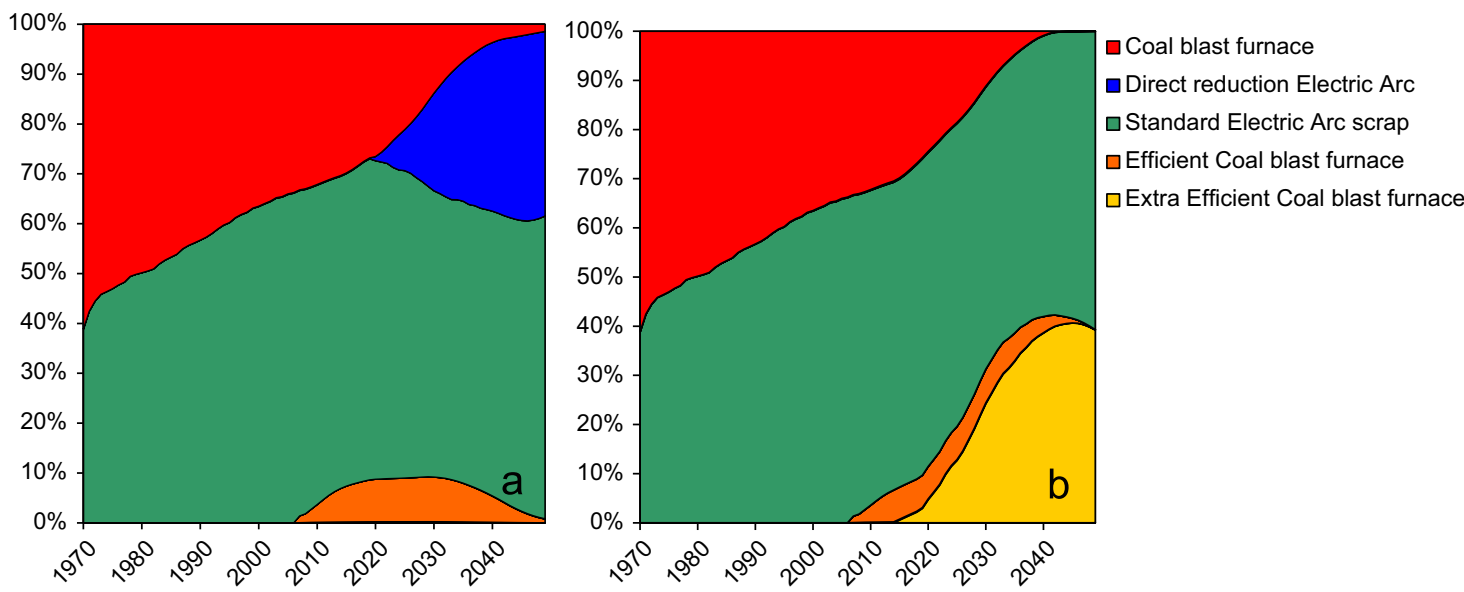

Fig. 6. Projection of shares in European steel production capacity, (a) in the baseline (b) when only very efficient blast furnaces are allowed to be built. 


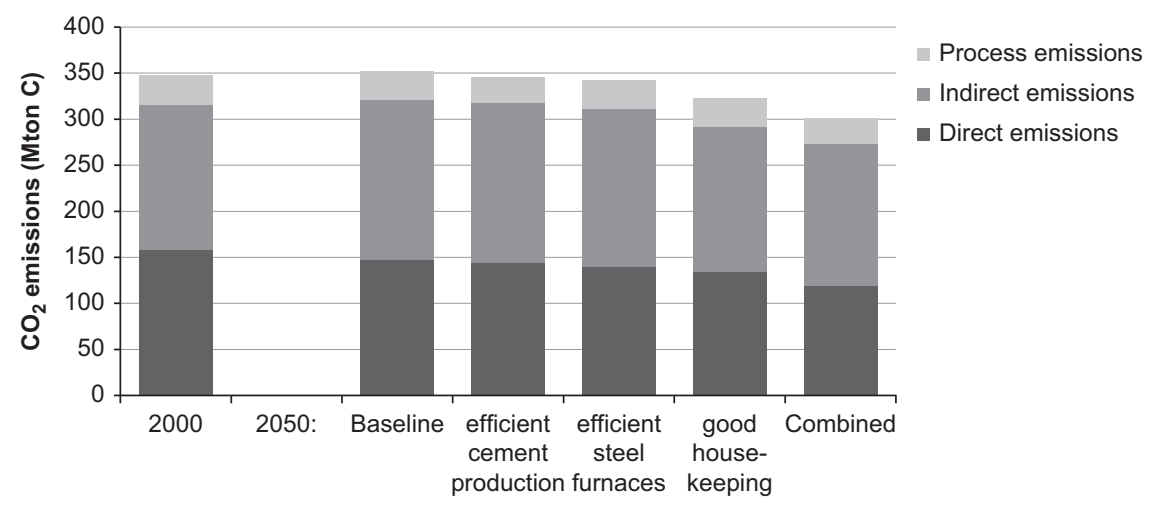

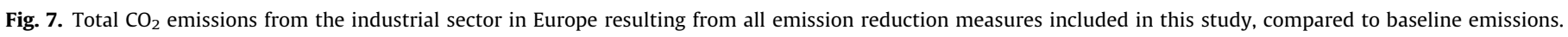

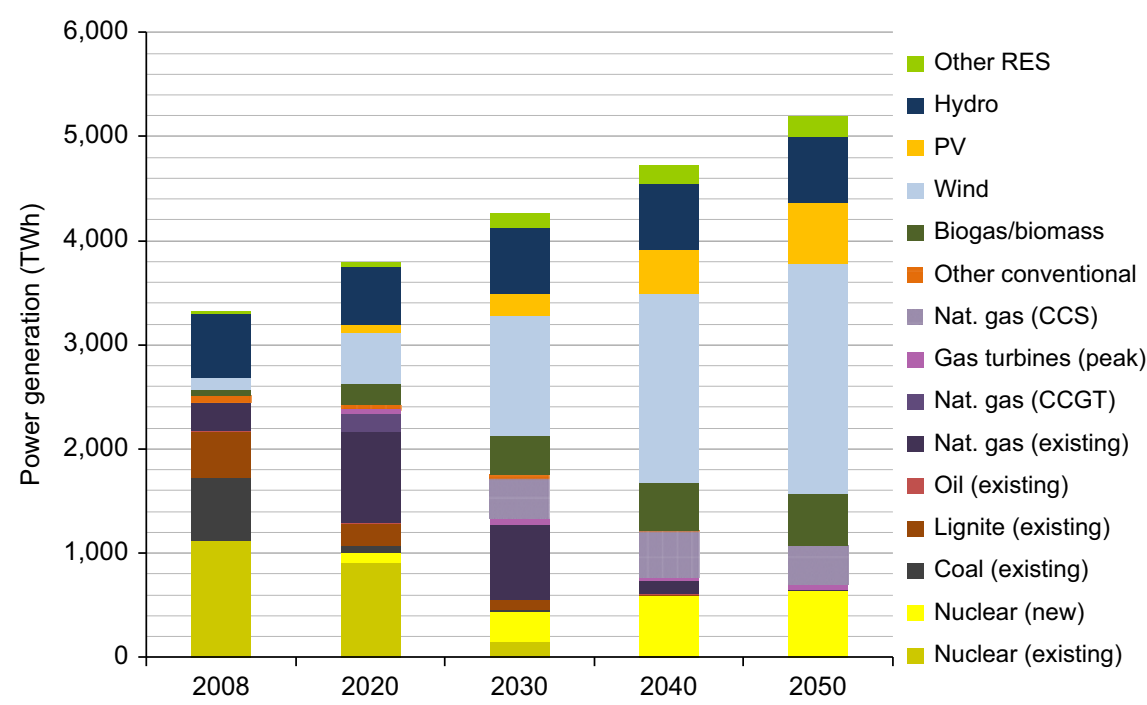

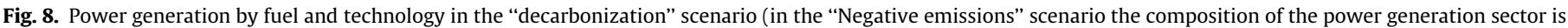
the same as in the "decarbonization" scenario, except for $80 \%$ of the biogas/biomass being used with BECCS).

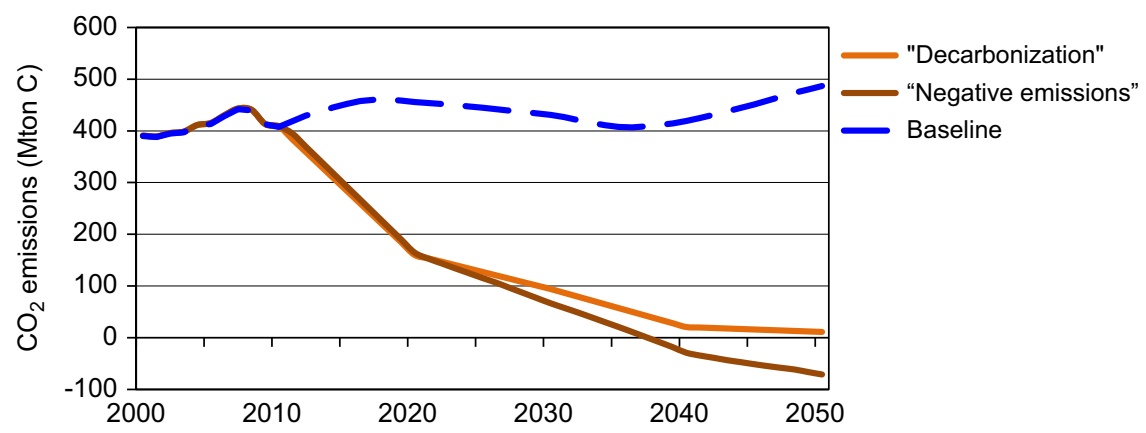

Fig. 9. $\mathrm{CO}_{2}$ emissions from the European power generation sector in the two scenarios with emission reduction measures, compared to baseline emissions.

within the range of other studies, as a recent meta-study by Fischedick et al. (2012) shows. Losses from transmission, storage and curtailment of electricity are projected to amount to $10 \%$ of the gross generation.

The change in composition of the power generation sector has far reaching consequences for $\mathrm{CO}_{2}$ emissions from the sector (Fig. 9). Both carbon tax scenarios show similar $\mathrm{CO}_{2}$ emissions up to 2020, as differences between the scenarios are only introduced after 2020. The availability of BECCS in the "negative emissions" scenario leads to $20 \%$ higher emission reductions in 2050 compared to the "decarbonization" scenario without BECCS. Negative emissions from BECCS could compensate shortcomings in emission reductions of other sectors by acting as a carbon sink. However, large scale CCS technology deployment depends on the adoption of a strong supportive policy framework, and the ability to deal with local opposition towards pilot $\mathrm{CO}_{2}$ storage projects; both are currently problematic at least in some European countries (Johnsson et al., 2010; Reichardt et al., 2012). Furthermore, the benefits of BECCS are controversial, especially if the assumption that biomass provides carbon neutral energy cannot be taken for granted (Gough and Upham, 2011).

It is also unclear whether CCS power plants, including BECCS plants, provide the necessary flexibility for a system with a high share of fluctuating renewables. Even though flexibly operated 


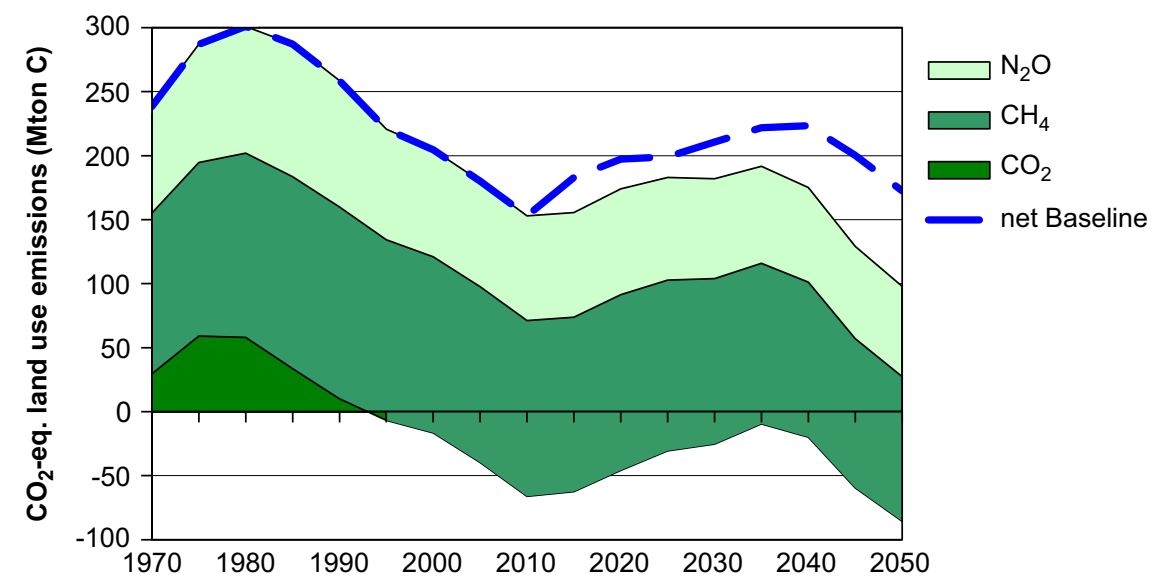

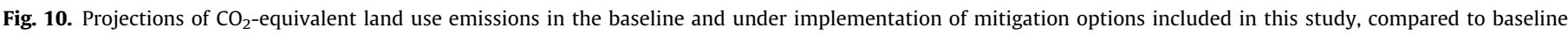
emissions.

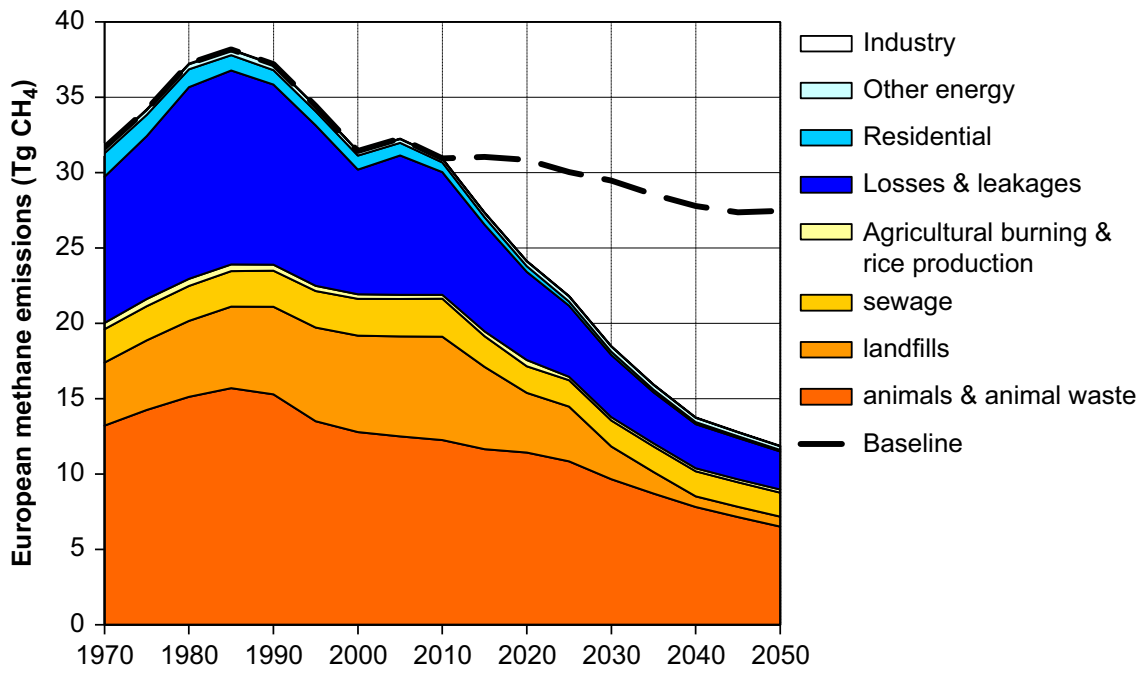

Fig. 11. Reduced non-natural methane emissions in Europe using control measures compared to total OECD baseline emissions.

coal-fired power plants with CCS may not cause insuperable technical constraints, flexible operation may have economic trade-offs such as decreased plant lifetime (due to thermal stress) or reduced capture efficiency at peak demand hours (because installing economically sensible capture capacity may induce partial bypassing of the capture unit) (Chalmers et al., 2009). A reduced (economic) flexibility of BECCS plants would imply a tradeoff between biomass as a flexible low-carbon technology and BECCS as a carbon sink. Whether or not the application of BECCS should be part of a decarbonization strategy depends on developments in other sectors as well. As biomass can be applied to mitigate emissions in all sectors, including applications with few other options to decrease emissions substantially, such as aviation, the most efficient usage could be determined in a sound cross-sectoral cost-benefit analysis.

The results shown in Fig. 9 are ceteris paribus (in the other sectors, no mitigation policies are implemented). As the mitigation options in other sectors may increase or decrease demand for electricity, an integrated analysis may lead to different reductions for the power generation sector. Section 3.7 provides such an integrated analysis.

\subsection{Agricultural sector}

The mitigation options for the agricultural sector are targeted at reducing $\mathrm{CO}_{2}$ and are based on $\mathrm{PBL}$ (2011). This report provides results for the combined effects of the measures in Europe. Overall, the measures cause a 6\% decrease in European demand for agricultural products by 2050 compared to the baseline, caused by dietary changes and improved supply efficiency. It is assumed that the measures are implemented globally, thus accounting for a price decrease in agricultural products as a result of lower agricultural demand.

The measures listed in Section 2.3.5 decrease net land-use related GHG emissions by about $43 \%$ by 2050 , as more agricultural land is converted to natural area (Fig. 10).

\subsection{Non- $\mathrm{CO}_{2}$ reduction}

The non- $\mathrm{CO}_{2}$ GHG reduction measures focus on black carbon (BC) and methane (Section 2.3.6). Baseline emissions of BC are expected to strongly decrease up to 2050. This can be mainly explained by declining air polluting emissions from the transport sector, due to current European legislation on air pollution policy measures up to 2030 (GAINS, 2011). This means that the additional reduction potential is limited, but nonetheless the measures achieve a reduction of $11 \%$ in BC emissions by 2050 relative to baseline.

For methane, the reductions are $44 \%$ of total baseline emissions by 2050 (Fig. 11). Together, the two measures lead to a 
reduction of about $7 \%$ of total baseline $\mathrm{CO}_{2}$-equivalent emissions by 2050 .

\subsection{Overview and integrated analysis}

Table 1 provides an overview of the emission reduction potential for all measures, when individually implemented. As expected, the largest absolute reduction potential is found in the power generation sector. The main reasons for this are that the power generation sector is responsible for the highest share of emissions by 2050 (Fig. 1) and that comprehensive measures are implemented here (i.e., a carbon tax combined with a renewable target).

The reductions from the individual options in Table 1 cannot simply be added up as end-use savings influence the supply of energy. In particular, the measures assumed in the industry and residential sectors lead to a net reduction of electricity demand (Fig. 12), while those in the transport sector increase total electricity demand from 2030 onwards as a result of an increased share of electric vehicles. All measures combined lead to a reduction in total electricity demand of $7 \%$ by 2030 and by $1 \%$ by 2050 .

It should be noted that so-far we have not accounted for rebound effects as a result of changed behaviour. According to Sorrell (2007), this rebound effect may lead to offset at least 10\% of the energy savings from any efficiency improvement.

We used the TIMER model using the two Power ACE scenarios to describe the decarbonization in the power generation sector. Fig. 13 shows that a combination of the reduction measures discussed in this study could reach a reduction level between $52 \%$ ("decarbonisation") and 63\% ("negative emissions") compared to 1990 levels.

Reductions are slightly larger when non- $\mathrm{CO}_{2}$ GHGs and emissions from land-use are included (Fig. 14). The total GHG emission reductions with respect to 1990 emission levels end up at 57\%

Table 1

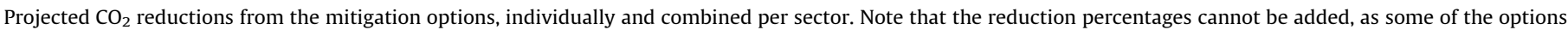
overlap and combinations of options may lead to price effects.

\begin{tabular}{|c|c|c|c|}
\hline Sector & Measure & $\begin{array}{l}\text { Percentage reduction of total } \\
\text { European emissions in } 2050 \text { (\%) }\end{array}$ & $\begin{array}{l}\text { Percentage reduction in } \\
\text { sectoral } \\
\text { emissions 2050, compared to } \\
\text { baseline }\end{array}$ \\
\hline \multirow[t]{2}{*}{ Transport } & $\begin{array}{l}50 \% \text { tax increase on fossil fuel combined with a } 35 \% \text { subsidy on } \\
\text { electric cars }\end{array}$ & 3.0 & $13 \%$ \\
\hline & $\begin{array}{l}25 \% \text { subsidy on high speed rail combined with a departure tax for air } \\
\text { travel }\end{array}$ & 1.4 & \\
\hline \multirow[t]{3}{*}{ Residential } & $\begin{array}{l}\text { Enforcing advanced heating technologies and highest building } \\
\text { insulation standards }\end{array}$ & 7.6 & $32 \%$ \\
\hline & Banning traditional light bulbs & 0.2 & \\
\hline & Enforcing only "A" Label appliances & 0.6 & \\
\hline \multirow[t]{3}{*}{ Industry } & lower clinker ratios in cement production & 0.3 & $15 \%$ \\
\hline & Enforcing advanced type steel furnaces & 0.7 & \\
\hline & enforcing good housekeeping & 3.4 & \\
\hline \multirow[t]{2}{*}{ Power generation } & "decarbonization" scenario & 33.7 & $97 \%$ \\
\hline & "negative emissions" scenario (incl. BECCS) & 42.8 & $115 \%$ \\
\hline \multirow[t]{4}{*}{ Agriculture $^{\mathrm{a}, \mathrm{b}}$} & Crop yield increase & 0.9 & $43 \%$ of $\mathrm{CO}_{2}$-eq emissions \\
\hline & Feed conversion and supply chain efficiency & 1.8 & \\
\hline & Changing Dietary preferences & 1.4 & \\
\hline & Improving forest and nature management & 0.6 & \\
\hline \multirow[t]{2}{*}{ Non- $\mathrm{CO}_{2}{ }^{\mathrm{a}}$} & $\begin{array}{l}\text { Methane control measures on fossil fuel production, animal waste, } \\
\text { landfills and wastewater }\end{array}$ & 6.7 & $38 \%$ of non $\mathrm{CO}_{2}$ emissions \\
\hline & BC control measures (mostly transport) & 0.1 & \\
\hline
\end{tabular}

${ }^{a}$ Reductions resulting from measures aimed at agriculture and non- $\mathrm{CO}_{2} \mathrm{GHGs}$ are provided in $\%$ of $\mathrm{CO}_{2}$ equivalent emission.

${ }^{b}$ The breakdown of reductions for the options in the agricultural sector is based on the global total in PBL (2010).

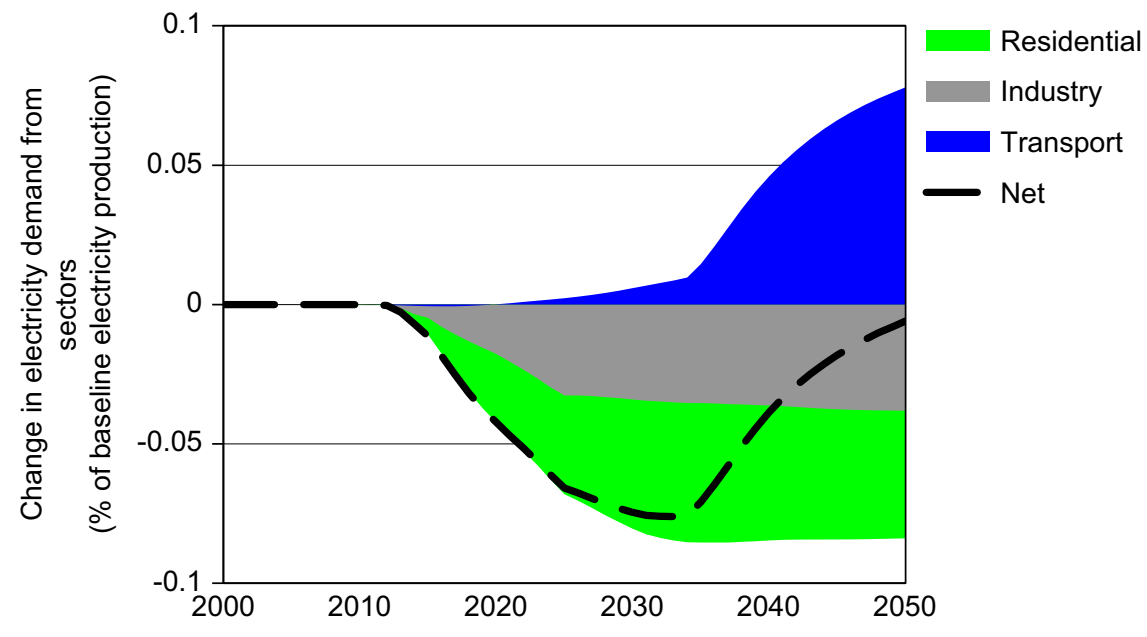

Fig. 12. Changes to the electricity demand by sectors compared to the baseline. 


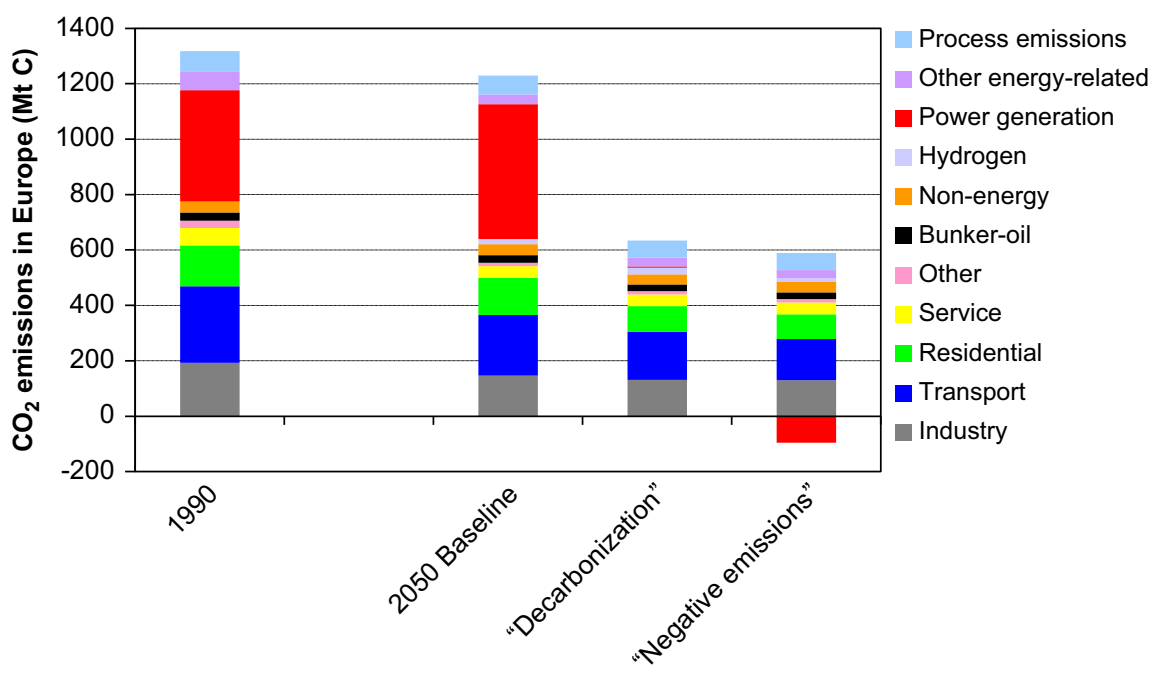

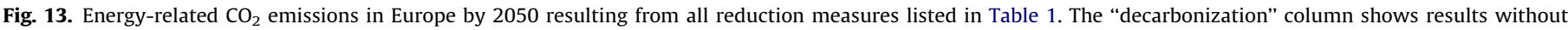

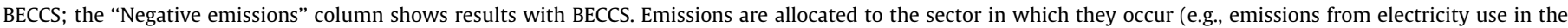
residential sector are allocated to the power generation sector).

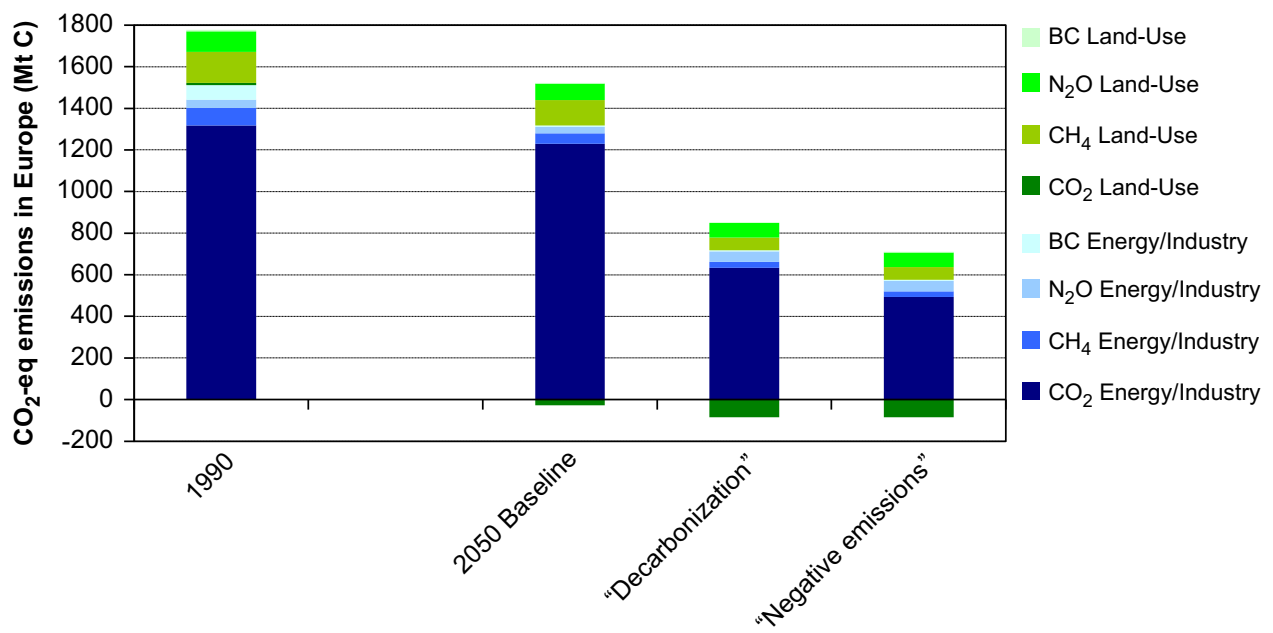

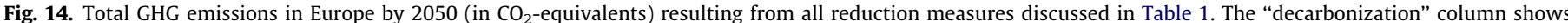
results without BECCS; the "Negative emissions" column shows results with BECCS.

and $65 \%$, respectively for the "decarbonization" and the "negative emissions" cases.

\section{Conclusions and discussion}

This study analysed the potential GHG emission reductions in Europe from specific mitigation options in the main emitting sectors with the objective to (1) gain more insight into the effectiveness of different specific measures, and (2) identify trade-offs between sectoral policies in achieving ambitious climate goals.

The combination of all options could reduce GHG emissions to 65\% below European $1990 \mathrm{CO}_{2}$-equivalent emissions by 2050 . Although this is less than the objective of the $\mathrm{EU}$ to reduce emissions by $80-95 \%$ relative to 1990 levels by 2050 , this does not imply that these reduction targets are infeasible. The set of measures is not exhaustive and does not represent a scenario for long-term EU climate targets. It does indicate, however, some idea of the effort involved: considerably more needs to be done than the already ambitious list of measures evaluated in this paper.

The analysis provides some insights into the effectiveness of measures across sectors. It confirms the finding of other modelling studies that the power generation sector is crucial in reaching deep emission reductions (Williams et al., 2012). The reasons are that (i) emissions from the electricity sector are projected to account for the largest share in total emissions by 2050, and (ii) power generation has the potential to achieve negative emissions by using carbon capture and sequestration technologies in combination with bio-fuel use (BECCS). The development of CCS technology and the societal acceptance of this technology therefore remain important for reaching ambitious climate targets.

This brings forward some points of discussion on the realism of the assumed measures and the technologies on which they depend. Besides uncertainties on CCS deployment (elaborated in Section 3.4), also the presented high shares of wind power and electric cars require considerable effort. Still, the rapid phasedown of fossil-fuelled cars presented in this study is not unprecedented in literature. For instance, the IEA Blue Map scenarios show a similar pathway globally (IEA, 2011). The current technological advancement and market readiness of electric vehicles in Europe seem to justify an optimistic penetration rate. Also the high shares of renewables (particularly wind energy) are within the range of existing literature. 
While being mindful about the uncertainties, the results of this study give insight into the following considerations on climate policy effectiveness.

First of all, the analysis shows that some of the most tangible measures, like enforcing efficient lighting or appliances, have only a very limited effect. Other measures that are not fully deployed under cost-optimal $2{ }^{\circ} \mathrm{C}$ scenarios, like advanced insulation, stimulating electric passenger vehicles, good housekeeping in industry and general methane control measures do seem to have a promising potential.

Second, we have seen examples of measures that where already partly considered in the baseline, such as the ban on incandescent light bulbs, efficient cement plants and black carbon control measures. In these cases, high levels of technological advancement and high energy prices in Europe already ensure an increasing share of compact fluorescent lamps, efficient cement production and decreasing emissions of black carbon.

Third, this study found important trade-offs between measures, both within and between sectors. For instance, a subsidy on electric cars could have the effect of battery electric vehicles replacing plugin hybrid electric vehicles, instead of traditional gasoline cars. This may reduce the effectiveness of such a subsidy.

Finally, we found that a bottom-up modelling of mitigation options allows for an assessment of the importance of controversial policies (like lowering meat consumption, or a departure tax on air travel) or policies that rely on physical limitations (like metal scarcity due to growth of battery powered transport). We argue that bottom-up modelling exercises, like the one presented here, provide a promising starting point to explore such explicit dynamics and policy choices, which are not covered in cost-optimal mitigation scenarios based on carbon tax regimes. Thereby, they may contribute to more realistic climate policy scenarios.

The downside of such bottom-up emission reduction studies is that the mitigation potential resulting from fuel switching is only partly considered. Fuel switching contributes a large part of the total mitigation potential in cost-optimal scenario studies, as for example shown by Blesl et al. (2010). However, fuel switching only happens at high prices for carbon intensive fuels, which are not considered in the measures for the residential and industrial sector. The most important drawback, however, is the fact that insights in overall costs for climate policy are less obvious. Specific measures may lead to higher climate policy costs. Then again, including more costly policy options does not imply that scenarios become less feasible, as illustrated by the current European commercial and political interest for electric cars and photovoltaics; two options that are barely deployed in cost-optimal scenarios.

\section{Acknowledgements}

This paper has been written as part of the RESPONSES project, co-funded by the European Commission within the Seventh Framework Programme. We would like to thank our colleagues in both the RESPONSES project and the OECD Environmental Outlook project for the joint work in these projects and the specific thoughts and comments they provided.

\section{References}

Blesl, M., Kober, T., Bruchof, D., Kuder, R., 2010. Effects of climate and energy policy related measures and targets on the future structure of the European energy system in 2020 and beyond. Energy Policy 38, 6278-6292.

Boermans, T., Petersdorff, C., 2007. $U$-values for Better Energy Performance of Buildings. Ecofys \& EURIMA, Cologne

Boskaljon, W.H., 2010. Modelling the Steel and Cement Industry; Abottom-up Addition to the TIMER Model, Department Science. Technology and Society. Utrecht university, Utrecht.
Bouwman, A.F., Kram, T., Klein Goldewijk, K., 2006. Integrated Modelling of Global Environmental Change. An Overview of IMAGE 2.4. Netherlands Environmental Assessment Agency, available at:〈www.mnp.nl/en〉, Bilthoven, The Netherlands.

Chalmers, H., Lucquiaud, M., Gibbins, J., Leach, M., 2009. Flexible operation of coal fired power plants with postcombustion capture of carbon dioxide. Journal of Environmental Engineering 135, 449-458.

Clarke, L., Edmonds, J., Krey, V., Richels, R., Rose, S., Tavoni, M., 2009. International climate policy architectures: overview of the EMF 22 International Scenarios. Energy Economics 31.

Korneef, J., can Breevoort, P., Hendricks, C., Hoogwijk, M., Koops, K., Koper, M., 2011. Potential for biomass and carbon dioxide caputure and storage. Ecofys and IEA.

DOE, U., 2011. Furnaces and boilers. U.S. Department of Energy.

Daioglou, V., van Ruijven, B.J., van Vuuren, D.P., 2012. Model projections for household energy use in developing countries. Energy 37, 601-615.

Dalkmann, H., Huizenga, C., 2010. Advancing Sustainable Low-Carbon Transport Through the GEF. Global Environment Facility, Washington, D.C.

Deetman, S., Pfluger, B., Hof, A., van Vuuren, D., Girod, B., van Ruijven, B., 2011. Assessment of Alternative Deep Emissions Reductions in Europe. Netherlands Environmental Assessment Agency, Bilthoven, p. 55.

EPA, 2006. Global Mitigation of Non- $\mathrm{CO}_{2}$ Greenhouse Gases. United States Environmental Protection Agency, Washington, DC, USA.

EU, 2008. Phasing out Incandescent Bulbs in the EU-Technical Briefing. Brussels.

EU, 2010a. DIRECTIVE 2010/31/EU on the energy performance of buildings. Official Journal of the European Union, Brussels.

EU, 2010b. Energy Labelling: Commission sets up New Energy Labels, Brussels.

Edenhofer, O., Knopf, B., Leimbach, M., Bauer, N., 2010. ADAM's modeling comparison project; intentions and prospects. The Energy Journal 31 (1), 7-10.

Engström, R., Carlsson-Kanyama, A., 2004. Food losses in food service institutions examples from Sweden. Food Policy 29, 203-213.

European Commission, 2011a. Energy Efficiency Plan 2011. Brussels.

European Commission, 2011b. Roadmap to a Single European Transport Area. Brussels.

Fischedick, M., Förster, H., Friege, J., Healy, S., Lechtenböhmer, S., Loreck, C., Matthes, F.C., Prantner, M., Samadi, S., Venjakob, J., 2012. Power Sector Decarbonisation: Metastudy. Öko-Institut e.V, Berlin, Germany.

Foster, F., 2010. The Air Travel Taxes Influencing How Far We Fly BBC News.

GAINS, 2011. Online database: greenhouse gas and air pollution interactions and synergies (GAINS) Europe. International Institute for Applied Systems Analysis.

Geurs, K.T., Nijland, H., Ruijven, B.v., 2011. Getting into the right lane for lowcarbon transport in the EU. In: Rothengatter, W., Hayashi, Y., Schade, W. (Eds.) Transport Moving to Climate Intelligence: New Chances for Controlling Climate Impacts of Transport after the Economic Crisis. Springer, New York, pp. 53-72.

Girod, B., van Vuuren, D.P., Deetman, S., 2012. Global Travel within the 2 Degree Climate Target. Energy Policy. 45, 152-166.

Gough, C., Upham, C., 2011. Biomass energy with carbon capture and storage (BECCS or Bio-CCS). Greenhouse Gas Science and Technology, 113 October 2011.

Graus, W., Blomen, E., Worrell, E., 2011. Global energy efficiency improvement in the long term: a demand- and supply-side perspective. Energy Efficiency 4, 435-463.

Held, A.M., 2011. Modelling the Future Development of Renewable Energy Technologies in the European Electricity Sector Using Agent-based Simulation. Department of Economics and Business Engineering-Institute of Industrial Production (IIP) University of the State of Baden-Wuerttemberg, Karlsruhe.

IEA, 2010. World Energy Outlook 2010. International Energy Agency, Paris, France.

IEA, 2011. Technology Roadmap Electric and Plug-in Hybrid Electric Vehicles. International Energy Agency/Organisation for Economic Co-operation and Development, Paris, France.

Isaac, M., van Vuuren, D.P., 2009. Modeling global residential sector energy demand for heating and air conditioning in the context of climate change. Energy Policy 37, 507-521.

Johnsson, F., Reiner, D., Itaoka, K., Herzog, H., 2010. Stakeholder attitudes on carbon capture and storage-an international comparison. International Journal of Greenhouse Gas Control 4, 410-418.

Kaya, D., Phelan, P., Chau, D., Ibrahim Sarac, H., 2002. Energy conservation in compressed-air systems. International Journal of Energy Research 26, 837-849.

Lucas, P., van Vuuren, D.P., Olivier, J.A., den Elzen, M.G.J., 2007. Long-term reduction potential of non- $\mathrm{CO}_{2}$ greenhouse gases. Environmental Science \& Policy 10, 85-103.

Lundqvist, J., 2009. Losses and waste in the global crisis. Reviews in Environmental Science and Biotechnology 8, 121-123.

Lüken, M., Edenhofer, O., Knopf, B., Leimbach, M., Luderer, G., Bauer, N., 2011. The role of technological availability for the distributive impacts of climate change mitigation policy. Energy Policy 39, 6030-6039.

Nordhaus, W.D., 2010. Economic aspects of global warming in a post-Copenhagen environment. Proceedings of the National Academy of Sciences.

OECD, 2012. OECD Environmental Outlook to 2050. Organisation for Economic Cooperation and Development, Paris, p. 350.

PBL, 2010. Rethinking Global Biodiversity Strategies: Exploring structural changes in production and consumption to reduce biodiversity loss. In: Brink, B.t. (Ed.), Netherlands Environmental Assessment Agency. PBL, Bilthoven, pp. 168.

PBL, 2011. EU Resource Efficiency Perspectives in a Global Context. PBL, Netherlands Environmental Assessment Agency, Bilthoven. 
Peeters, L., Van der Veken, J., Hens, H., Helsen, L., D'haeseleer, W., 2008. Control of heating systems in residential buildings: current practice. Energy and Buildings $40,1446-1455$.

Pfluger, B., Schleich, J., 2012. Short Summary of Preliminary Findings for the European Electricity Sector. Draft Version.

Reddy, M.S., Boucher, O., 2007. Climate impact of black carbon emitted from energy consumption in the world's regions. Geophysical Research Letters 34, L11802.

Reichardt, K., Marth, H., Schleich, J., 2012. Effects of the Policy Mix on the Development, Demonstration and Diffusion of Low-carbon Power Generation Technologies. Fraunhofer Institute for Systems and Innovation Research, Karlsruhe, Germany.

Rogelj, J., Hare, W., Lowe, J., van Vuuren, D.P., Riahi, K., Matthews, B, Hanaoka, T. Jiang, K., Meinshausen, M., 2011. Emission pathways consistent with a 2[thinsp][deg]C global temperature limit. Nature Climate Change 1, 413-418.

Sensfuß, F. 2007. Assessment of the Impact of Renewable Electricity Generation on the German Electricity Sector; An Agent-based Simulation Approach, Fakultät für Wirtschaftswissenschaften der Universität Karlsruhe. Universität Karlsruhe, Karlsruhe, p. 219.

Sorrell, S., 2007. The Rebound Effect: An Assessment of the Evidence for Economy-wide Energy Savings from Improved Energy Efficiency. UK Energy Research Centre.

Stehfest, E., Bouwman, L., van Vuuren, D., den Elzen, M., Eickhout, B., Kabat, P., 2009. Climate benefits of changing diet. Climatic Change 95 83-102-102.

Taylor, M., Tam, C., Gielen, D.J., 2006. Energy Efficiency and $\mathrm{CO}_{2}$ Emissions from the Global Cement Industry. IEA, Paris, p. 12.

UN, 2008. World Population Prospects: he 2008 Revision. United Nations Department for Economic and Social Information and TPolicy Analysis, New York, NY.

UNEP and WMO, 2011. Integrated Assessment of Black Carbon and Tropospheric Ozone-Summary for Decicion Makers. In: Ullstein, B. (Ed.), UNEP and WMO.

UNFCCC, 2009. Copenhagen Accord, in: Change, U.N.F.C.o.C. (Ed.), Copenhagen.

UNFCCC, 2011. Report of the Conference of the Parties on its Sixteenth Session, Held in Cancun from 29 November to 10 December 2010, 16th Conference of the Parties. United Nations Framework Convention on Climate Change, Cancun.

UNFCCC, 2012. Greenhouse Gas Inventory Data.

Viidanoja, J., Sillanpää, M., Laakia, J., Kerminen, V.-M., Hillamo, R., Aarnio, P., Koskentalo, T., 2002. Organic and black carbon in PM2.5 and PM10: 1 year of data from an urban site in Helsinki, Finland. Atmospheric Environment 36, 3183-3193.

van Vuuren, D., Riahi, K., 2011. The relationship between short-term emissions and long-term concentration targets. Climatic Change 104, 793-801.

van Vuuren, D., Stehfest, E., den Elzen, M., Kram, T., van Vliet, J., Deetman, S., Isaac, M., Klein Goldewijk, K., Hof, A., Mendoza Beltran, A., Oostenrijk, R., van Ruijven, B., 2011. RCP2.6: exploring the possibility to keep global mean temperature increase below $2{ }^{\circ} \mathrm{C}$. Climatic Change 109, 95-116.

van Vuuren, D.P., van Ruijven, B., Hoogwijk, M., Isaac, M., de Vries, H.J.M., 2006 TIMER 2: model description and application. In: Bouwman, A.F., Kram, T., Klein Goldewijk, K. (Eds.), Integrated Modelling of Global Environmental Change. An Overview of IMAGE 2.4. Netherlands Environmental Assessment Agency (MNP), Bilthoven, the Netherlands.

van Vuuren, D.P., den Elzen, M.G.J., Lucas, P.L., Eickhout, B., Strengers, B.J., van Ruijven, B., Wonink, S., van Houdt, R., 2007. Stabilizing greenhouse gas concentrations at low levels: an assessment of reduction strategies and costs. Climatic Change 81, 119-159.

van Vuuren, D.P., Riahi, K., Moss, R., Edmonds, J., Thomson, A., Nakicenovic, N. Kram, T., Berkhout, F., Swart, R., Janetos, A., Rose, S.K., Arnell, N., 2012. A proposal for a new scenario framework to support research and assessment in different climate research communities. Global Environmental Change 22 21-35.

van Ruijven, B.J., van Vuuren, D.P., de Vries, B.J.M., Isaac, M., van der Sluijs, J.P. Lucas, P.L., Balachandra, P., 2011. Model projections for household energy use in India. Energy Policy 39, 7747-7761.

Williams, J.H., DeBenedictis, A., Ghanadan, R., Mahone, A., Moore, J., Morrow, W.R., Price, S., Torn, M.S., 2012. The technology path to deep greenhouse gas emissions cuts by 2050: the pivotal role of electricity. Science 335, 53-59.

Willett, M.D.W.C. (Ed.), Simon \& Schuster, New york.

Worrell, E., Galitsky, C., 2008. Energy Efficiency Improvement and Cost Saving Opportunities for Cement Making. Ernest Orlando Lawrence Berkeley National Laboratory, Berkeley, CA

Worrell, E., Martin, N., Price, L., 1999. Energy Efficiency and Carbon Dioxide Emissions Reduction Opportunities in the U.S. Iron and Steel Sector. Ernest Orlando Lawrence Berkeley National Laboratory, Berkeley, CA, p. 52. 